NBER WORKING PAPER SERIES

\title{
THE IMPACT OF INFLATION ON \\ BUDGETARY DISCIPLINE
}

Joshua Aizenman

Ricardo Hausmann

Working Paper 5338

\section{NATIONAL BUREAU OF ECONOMIC RESEARCH 1050 Massachusetts Avenue \\ Cambridge, MA 02138 \\ November 1995}

We wish to thank Ivan Sergio Guerra and Martin Loser for econometric support. We would like to thank Alberto Alesina, Karnit Flug, Roberto Perotti, Klaus Schmidt-Hebbel and Ernesto Talvi for useful comments on an earlier draft. All errors are ours. This paper is part of NBER's research program in Monetary Economics. Any opinions expressed are those of the authors and not those of the National Bureau of Economic Research.

() 1995 by Joshua Aizenman and Ricardo Hausmann. All rights reserved. Short sections of text, not to exceed two paragraphs, may be quoted without explicit permission provided that full credit, including $\odot$ notice, is given to the source. 


\title{
THE IMPACT OF INFLATION ON \\ BUDGETARY DISCIPLINE
}

\begin{abstract}
This paper investigates budgetary rules for an economy characterized by inflation and volatile relative prices. We view the budgetary process as a limited contingencies contract between the treasury and the ministers. The budgetary process allows a minister, whose realized real budget falls short of a threshold, to ask for a budget revision. Upon cost verification by the treasury, the minister obtains the extra funds needed to meet the expenditure threshold level. The contract sets both the projected budget and the threshold real expenditure that justifies budget revisions. We identify the efficient contract, and show that for significant state verification costs and for low volatility, the contract is non contingent (i.e., a nominal contract). For volatility significant enough the contract becomes state contingent -- it reduces the initial allocation [i.e., the projected budget], and reduces the threshold associated with budgetary revisions. Both adjustments imply that in volatile economies the projected revenue understates the realized budget, hence the average budget error is positive. As the volatility increases, the contract converges to a full ex-post indexation. Hence, one of the costs of inflation is that nominal contracts lose their disciplining role in determining the real allocation. Instead, the economy shifts towards more costly arrangements, like ex-post indexation, where the discipline is accomplished by constant monitoring.

The last part of the paper uses the data from 12 Latin American countries to test the model's predictions. Our tests confirm that in an inflationary environment the planned budget is under-predicting the realized one -- higher inflation increases the budget error and hence the average budget error is positive.
\end{abstract}

Joshua Aizenman

Department of Economics

Dartmouth College

Hanover, NH 03755

and NBER
Ricardo Hausmann

Chief Economist

Inter-American Development Bank

1300 New York Avenue, NW

Washington, DC 20577 


\section{Introduction}

The purpose of this paper is to investigate budgetary rules for an economy characterized by inflation and volatile relative prices. In the absence of shocks, the design of the budget is simple -the treasury allocates funds once in every budgetary cycle. In the presence of volatile shocks, we would observe occasional budgetary revisions, the outcome of which is that the actual expenditure differs from the projected one. For example, Figure 1 summarizes the "budget error" (defined as the percentage gap between the actual and the projected nominal expenditure) and inflation tax rate (defined by inflation/[1+ inflation]) for Venezuela, 1980-1994. ${ }^{1}$ The Figure suggests that, at least for Venezuela, budget errors and inflation are positively correlated. ${ }^{2}$ Furthermore, the dominance of positive budget errors suggests a systematic bias for "under projecting" the budget. The purpose of this paper is two fold. First, we describe a model that explains the patterns observed in Figure 1 as the outcome of a contract between the treasury and ministers in a volatile environment, where information gathering is costly. Second, we test and validate some of the model's predictions for 12 Latin American countries.

The departure point of our framework is that higher inflation comes with higher volatility of relative prices. ${ }^{3}$ The positive association between relative price volatility and inflation implies that a simple indexation rule that adjusts the budget of various ministers to the realized inflation fails from stabilizing the fiscal expenditure in an inflationary environment. Such a rule will overcompensate activities which benefit from a cost shock smaller than inflation, at the expense of activities the cost shock of which exceeds inflation. Hence, a budgetary rule that attempts to

1 The ratio "inflation/[1+ inflation]" measures the implicit tax rate imposed by inflation, and is bounded between values close to zero and 1 .

2 Figure $1 \mathrm{~b}$ reports the association between the budget error and the inflation tax rate. The $t$ values of the constant and the slope are $[-0.07,2.53]$, respectively. 3 This point was documented by a voluminous literature. See Cukierman (1984) for an interpretation of this observation and for further references. 
stabilize fiscal expenditure should compensate for cost specific shocks. Inferring the relevant price information, however, may be costly to the treasury. First, there are the direct information gathering costs. Relying on the information provided by ministers may not ease the challenge of information gathering. In the absence of monitoring, ministers have the incentives to overstate their cost shock, in order to increase their budgetary share. Hence, the second source of information cost is the need to monitor ministers to prevent inflated cost reports. Both reasons suggest that in order to compensate a minister for the true cost shock, the treasury must spend real resources on monitoring and verification.

Our task is to explain the budgetary process in these circumstances. Our methodology views the budgetary process as a limited contingencies contract between the treasury and the ministers, where the treasury determines the contract recognizing the presence of several costs. First, deviations of the actual real fiscal expenditure from a target are costly (fiscal consumption smoothing). Second, attempts to remedy these deviations are costly due to the need to spend resources on state verification, as explained above. Furthermore, the delivery of extra funds in a mid budgetary cycle may involve extra costs. The treasury allocates at the beginning of each budget cycle a nominal budget, referred to as the projected budget. The real value of the projected budget is determined by the realization of the cost shock, and is revealed to each minister. The budget's contingent aspect allows a minister whose realized real budget falls short of a threshold to ask for a budget revision. Upon cost verification by the treasury, the minister obtains the extra funds needed to meet the expenditure threshold level.

We identify the efficient contract for the case where the distribution of the cost shock and the expenditure target are exogenously given. The contract sets endogenously two margins: the initial nominal budget [the projected budget], and the threshold real expenditure that justifies budget revisions. We show that for volatile economies the projected revenue understates the realized budget, hence the average budget error is positive. This bias stems from the asymmetric nature of the budgetary process, where budget revisions are one sided -- only ministers confronting a large cost shock engage in budget revisions. Ministers confronting a favorable cost 
shock benefit from a windfall gain, overspending the treasury target. The treasury may curb this overspending by reducing the initial allocation, which in turn implies a lower projected budget. Such a strategy comes with costs, as ministers miss more frequently the expenditure target. Hence, it calls for a lower budget revision threshold. This in turn implies that ministers will engage more frequently in budget revisions, necessitating more spending on cost verification. The desirable contract sets the two margins optimally, balancing the relevant costs and the benefits.

Our analysis shows that for significant state verification costs and low volatility, the contract is non contingent - it sets the threshold high enough so that no budget revisions are observed. The corresponding initial allocation is set at a level that yields an expected expenditure that falls short of the target by a second order magnitude [i.e., a magnitude proportional to the variance of the percentage cost shock]. For a volatility significant enough the contract becomes state contingent -- it reduces the initial allocation [i.e., the projected budget], and reduces the threshold associated with budgetary revisions. Both adjustments imply that revisions are observed. Further increase in volatility is shown to reduce both the initial allocation, as well as the threshold associated with budget revisions. Both effects imply that budget projections systematically underestimate the actual budget, and that volatility raises the resource transferred in mid term. As the volatility increases, the contract converges to a full ex-post indexation. This is accomplished by reducing both the initial allocation and the revision trigger so that we approach continuous revisions, ensuring that the real expenditure is close to the ideal expenditure. Thus, our analysis suggests that the interaction between volatility and verification costs determines ultimately how far the realized budgetary process is from a nominal, non-contingent contract [alternatively, how close is it to a real contract that induces ex-post indexation].

The last part of the paper uses the data from 12 Latin American countries to test the model's prediction that higher inflation will increase the budget error, and that in an inflationary environment the planned budget is under predicting the realized one. Our tests confirm these predictions, and show that both the expected and unexpected inflation increase the budget error. 
Before turning to the paper, it is useful to present it in the context of the existing literature. The costly state verification framework is a useful way of explaining contracts that allow for limited contingencies, as was shown by Townsends $[1979,1988]{ }^{4}$ There is a close parallel between our discussion and the literature on optimal indexation, as the degree of indexation determines the extent to which a nominal contract determines also the real magnitude of resources delivered. 5

Section 2 of the paper describes a model of costly budget revisions for the case where there is only one source of volatility, due to idiosyncratic cost shocks. We characterize the optimal design of the budgetary process. Section 3 shows that the qualitative predictions of Section 2 continue to hold for the case where there are several sources of volatility, including the possibility of random inflation that is positively correlated with adverse real shocks. Section 4 describes several tests of the model's predictions for 12 Latin American countries. Section 5 closes with a discussion of possible extensions.

4 For applications of the costly state verification model in Macroeconomics see Diamond (1984) who explains the optimality of a debt contract between a bank and an entrepreneur, and Calvo and Kaminsky [1991] who explain defaults in the presence of sovereign risk.

5 There exists a significant literature dealing with strategic re negotiation [for a review and further references see Fundenberg and Tirole (1991)]. On some macroeconomic implications of wage re-negotiation see Aizenman (1984) and Cantor (1988). 


\section{The Model}

Consider an administration composed of the treasury and $n$ ministers, indexed by i $(i=$ $1, \ldots, n)$. At the beginning of the budget cycle the treasury allocates the nominal budget for period minister $\mathrm{i}, B_{i, t}$. The realized real budget is $b_{i, t}=\frac{B_{i, t}}{P_{i, t}},\left[P_{i, t}\right.$ stands for the cost of public good i at

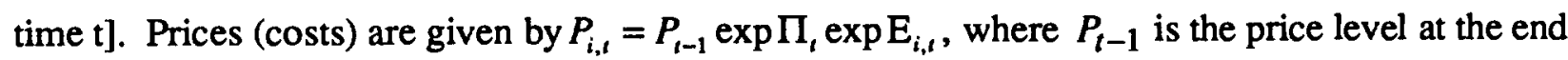
of the previous period, $\exp \Pi_{t}$ is (approximately) one plus the overall inflation, and $\exp E_{i, t}$ is the cost shock, specific to sector i. Each minister has private information regarding his/her cost

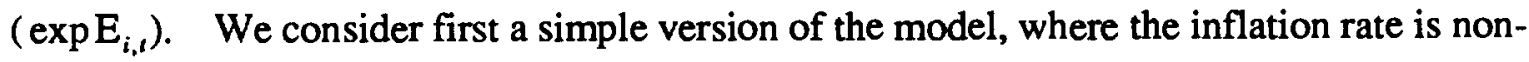
stochastic and the overall price level is known at the beginning of the period, $P_{t}=P_{t-1} \exp \Pi_{t, 0}$. In the next section we extend the model, dealing with the case where both inflation and relative prices are stochastic.

Let us define the percentage cost shock by $\varepsilon_{i, l}=1-\exp \left[-\mathrm{E}_{i, l}\right]$. We assume that the cost shocks $\varepsilon_{i, t}$ are i.i.d. distributed across ministers with zero mean, and variance $V_{\varepsilon}$. Henceforth we suppress the time subscript, and denote the planned real budget by $b_{i}^{p}, b_{i}^{p}=\frac{B_{i}}{P_{0}}$, where $P_{0}=P_{-1} \exp \left[\Pi_{0}\right]$ is the expected overall price level. Thus, the real budget of minister $\mathrm{i}$ [in the absence of budget revisions] is

(1) $\quad b_{i}=b_{i}^{p}\left[1-\varepsilon_{i}\right]$

\subsection{Budget revision rules}

Suppose that the treasury follows a trigger rule. The budget is revised in mid term only if the realized real expenditure falls short of a threshold level. The threshold is defined as a fraction $(1-\tau)$ of the planned budget $[-1 \leq \tau \leq 1]$. A revision implies that the minister is allocated the funds needed to meet the threshold. Hence, the actual real budget [denoted by $b_{i}^{a}$ ] is: 
(2) $\quad b_{i}^{a}= \begin{cases}b_{i}^{p}\left[1-\varepsilon_{i}\right] & \text { if } \quad b_{i}^{p}\left[1-\varepsilon_{i}\right]>b_{i}^{p}[1-\tau] \\ b_{i}^{p}[1-\tau] & \text { if } \quad b_{i}^{p}\left[1-\varepsilon_{i}\right] \leq b_{i}^{p}[1-\tau]\end{cases}$

Alternatively,

$$
\text { (2') } \quad b_{i}^{a}= \begin{cases}b_{i}^{p}\left[1-\varepsilon_{i}\right] & \text { if } \tau>\varepsilon_{i} \\ b_{i}^{p}[1-\tau] & \text { if } \tau \leq \varepsilon_{i}\end{cases}
$$

If the budget is revised, the minister obtains a nominal transfer of 6,7

(3) $\Delta B_{i}=P_{0} b_{i}^{p} \frac{\varepsilon_{i}-\tau}{1-\varepsilon_{i}} \cong P_{0} b_{i}^{p}\left[\varepsilon_{i}-\tau\right]$

Implementing (3) requires knowledge of the realized cost shock. Inferring this information is costly -- a budget revision for minister i implies that $\mathbf{k}$ resources are spent on "state verification." 8

Let the "ideal" real fiscal expenditure be $g_{i} \cdot 9$ The treasury has two instruments: it sets the projected budget $\left[b_{i}^{p}\right]$ as a fraction $1-\phi$ of the budget target $g_{i}\left\{\right.$ i.e., $\left.b_{i}^{p}=g_{i}[1-\phi]\right\}$, and it determines the revision trigger $[\tau]$. The projected budget is allocated at the beginning of the

6 To ensure real expenditure of $b_{i}^{p}[1-\tau]$ the minister needs a nominal budget of $b_{i}^{p}[1-\tau] P_{o} \exp E_{i}=B_{i}^{p}[1-\tau] \exp E_{i}=B_{i}^{p} \frac{1-\tau}{1-\varepsilon_{i}}$. The needed nominal transfer is $\Delta B_{i}=B_{i}^{P}[1-\tau] \exp E_{i}-B_{i}^{P}=B_{i}^{p}\left[\frac{1-\tau}{1-\varepsilon_{i}}-1\right]=B_{i}^{p}\left[\frac{\varepsilon_{i}-\tau}{1-\varepsilon_{i}}\right]$

7 The approximation in (3) is valid as long as the support of the cost shock is not "too large."

8 In the presence of moral hazard, spending these resources also prevent unfounded demands on behalf of the ministers. For further discussion of this issue see Section 2.2. 9 This is the desirable expenditure with full information and in the absence of shocks. 
period. 10 Following the realization of the cost shock ministers confronting large enough adverse cost shock would apply for a budget revision.

The treasury faces several costs:

- Deviation of the realized fiscal expenditure from a fiscal target gi are costly [fiscal consumption smoothing].

- Budget revisions are costly. It requires costly state verification. Furthermore, mid term delivery of extra resources may cost more than delivering the same resource ex-ante.

We postulate a loss function $\mathrm{L}$ that recognizes these costs:

(4) $L= \begin{cases}v\left[g_{i}-b_{i}^{a}\right]^{2} & \text { no budget revision } \\ v\left[g_{i}-b_{i}^{a}\right]^{2}+k+(1+\lambda) \frac{\Delta B_{i}}{P_{0}} & \text { budget revision }\end{cases}$

where $v$ measures the cost of the quadratic deviation from the planned budget target, and $1+\lambda$ measures the cost of mid term delivery of public funds. Applying our previous definitions the loss function can be restated as:

(5) $L= \begin{cases}v\left[g_{i}\left[1-(1-\phi)\left(1-\varepsilon_{i}\right)\right\}\right]^{2} & \text { if } \tau>\varepsilon_{\mathrm{i}} \\ v\left[g_{i}\{\{1-(1-\phi)(1-\tau)\}]^{2}+k+(1+\lambda) g_{i}(1-\phi) \frac{\varepsilon_{i}-\tau}{1-\varepsilon_{i}}\right. & \text { if } \tau \leq \varepsilon_{\mathrm{i}}\end{cases}$

10 Thus, the treasury allocates at the beginning of the period $B_{i}^{p}=g_{i}(1-\phi) P_{0}$, where $B_{i}^{p}$ stands for the projected nominal budget. 
The treasury is assumed to maximize the expected loss function, treating the real target $g_{i}$ and the distribution of the cost shock as exogenous. Let $f(\varepsilon)$ be the density function of the cost shock, defined for support $\underline{\varepsilon} \leq \varepsilon \leq \bar{\varepsilon}$. Thus, $100(\bar{\varepsilon}-\underline{\varepsilon})$ is the range of the percentage price shock, and thus $\bar{\varepsilon}<1 ; \underline{\varepsilon} \leq 0.11$ Hence

$$
\begin{aligned}
& E[L]= \\
& \text { (6) } v_{\underline{\varepsilon}}^{\tau}\left[g_{i}(1-(1-\phi)(1-\varepsilon)\}\right]^{2} \mathrm{f}(\varepsilon) \mathrm{d} \varepsilon+\left[v\left[g_{i}\{1-(1-\phi)(1-\tau)]\right]^{2}+k\right] \int_{\tau}^{\bar{\varepsilon}} \mathrm{f}(\varepsilon) \mathrm{d} \varepsilon \\
& +(1+\lambda) g_{i}(1-\phi) \int_{\tau}^{\bar{\varepsilon}} \frac{\varepsilon-\tau}{1-\varepsilon} \mathrm{f}(\varepsilon) \mathrm{d} \varepsilon
\end{aligned}
$$

The values of $(\phi, \tau)$ define the budgetary process, and are obtained as the solution to $M I N\{E[L]\}$

There are two limiting cases of the budgetary process -- a nominal contract $[\tau=\bar{\varepsilon}]$ and a full ex-post indexation $[\tau=\underline{\varepsilon}$ ]. A nominal contract implies that no budget revisions are allowed, hence the revision threshold is set at the upper limit of the support. Full ex-post indexation implies that budgetary revisions are observed in all states of nature; hence the revision threshold is set at the lower limit of the support. In general, the budgetary process will yield a contract that is in between these two extremes.

For a given budgetary process we define the budgetary error as the percentage difference between the actual and the planned budget:

$$
b e=\frac{B_{i}^{a}-B_{i}^{p}}{B_{i}^{p}}=\frac{\Delta B_{i}}{B_{i}^{p}}
$$

Applying (3) the expected budget error is

$$
E[b e]=\int_{\tau}^{\bar{\varepsilon}} \frac{\varepsilon_{i}-\tau}{1-\varepsilon_{i}} f(\varepsilon) \mathrm{d} \varepsilon
$$

11 Note that $\bar{\varepsilon}<1$ because prices are positive; $\underline{\varepsilon} \leq 0$ because the mean of the cost shock is normalized to zero. 


\section{Claim 1}

a. In an internal equilibrium [i.e., equilibrium where budget revisions are observed] lower state verification costs $(\mathrm{k})$ or lower cost of funds $(\lambda)$ reduces the budget revision trigger, increasing thereby the frequency of budget revisions -- $\frac{\partial \tau}{\partial k}>0, \frac{\partial \tau}{\partial \lambda}>0$. Under a weak condition, lower state verification cost will also reduce the initial allocation -- $\frac{\partial \phi}{\partial k}<0.12$

b. In an equilibrium where the contract is non-contingent [i.e., where no budget revisions are allowed] $\phi=\frac{V_{\varepsilon}}{1+V_{\varepsilon}}$. Hence, the projected budget falls short of the target $\mathrm{g}$ at a rate proportional to the variance of the percentage cost shock.

c. In an equilibrium where the contract induces ex-post indexation, the expected budgetary error equals $\int_{\varepsilon}^{\bar{\varepsilon}} \frac{1-\underline{\varepsilon}}{1-\varepsilon_{i}} f(\varepsilon) \mathrm{d} \varepsilon-1 \cong-\underline{\varepsilon}$. With full ex-post indexation the optimal allocation is determined by $\underline{\underline{\phi}}=\frac{-\underline{\varepsilon}}{1-\underline{\varepsilon}}\left[1-\frac{1+\lambda}{(1-\underline{\varepsilon}) \underline{\varepsilon} 2 g v} E\left[\frac{1-\underline{\varepsilon}}{1-\varepsilon}-1\right]\right] \cong \frac{-\underline{\varepsilon}}{1-\underline{\varepsilon}}\left[1+\frac{1+\lambda}{(1-\underline{\varepsilon}) 2 g v}\right] .13$ Hence, a raise in volatility that increases the range of the cost shock reduces the initial allocation.

Proof. See the Appendix.

Full ex-post indexation and a nominal contract with no budget revisions serve to define the limiting cases. Most contracts, however, may be in between these two extremes. We turn now to characterize the full range of possible contracts. To gain further insight, consider the case where the cost shock $(\varepsilon)$ follows a specific distribution. Assume that $\varepsilon$ is uniformly distributed in the interval $[-0.5 \alpha,+0.5 \alpha], 0 \leq \alpha \leq 2$. In these circumstances the loss function reduces to:

12 The condition is $0.5<(1-\phi)(1-\tau)-$ budget revisions should lead to real expenditure that equals at least half $g$ ( recall that $g$ is the desirable expenditure).

13 The approximations in these equations are valid as long as the support of the cost shock is not "too large." 


$$
\begin{aligned}
& E[L]= \\
& v \int_{-0.5 \alpha}^{\tau}\left[g_{i}(1-(1-\phi)(1-\varepsilon)\}\right]^{2} \frac{1}{\alpha} \mathrm{d} \varepsilon+\left[v\left[g_{i}[1-(1-\phi)(1-\tau))\right]^{2}+k\right] \int_{\tau}^{0.5 \alpha} \frac{1}{\alpha} \mathrm{d} \varepsilon \\
& +(1+\lambda) g_{i}(1-\phi) \int_{\tau}^{0.5 \alpha} \frac{\varepsilon-\tau}{1-\varepsilon} \frac{1}{\alpha} \mathrm{d} \varepsilon
\end{aligned}
$$

and the expected budgetary error is

$$
E[b e]=\int_{\tau}^{0.5 \alpha} \frac{\varepsilon_{i}-\tau}{1-\varepsilon_{i}} \frac{1}{\alpha} \mathrm{d} \varepsilon=\frac{(1-\tau) \ln \frac{1-\tau}{1-0.5 \alpha}-(0.5 \alpha-\tau)}{\alpha}
$$

Following some tedious derivations one can show that in an internal equilibrium [where budget revisions are observed] higher volatility increases the frequency of budget revisions, and reduces the initial allocation to ministers $\frac{\partial \phi}{\partial \alpha}>0 ; \quad \frac{\partial[\tau]}{\partial \alpha}<0 ; \quad \frac{\partial[\tau / \alpha]}{\partial \alpha}<0$.

These results imply that inflation and the induced higher volatility reduces the allocative role of a budget. There is inherent asymmetry in behavior -- a large enough adverse shock triggers a costly revision of the budget. Ministers that face a favorable cost shock enjoy windfall gain, and do not engage in budget revisions, leading to excessively high fiscal consumption. A lower projected budget reduces the incidence of "overspending" in good states [i.e., where the cost is low], but increases the cost of under consumption in bad states of nature [where cost is high]. Similarly, a lower budget revision trigger increases the expected budget revision costs [the sum of State verification cost and the cost of mid term funds], but reduces the expected cost of improper fiscal consumption when costs are high. The treasury sets its policies as to balance [at the margin] these effects. A higher volatility increases the expected cost of over expenditure, leading to a lower initial allocation. To compensate for the resultant loss in expenditure in states where the costs are high, the treasury reduces the revision threshold, increasing thereby the incidence of budgetary revisions. These considerations imply that 


\section{Claim 2}

Higher volatility of cost shocks increases the budget error.

Proof: See the Appendix

To gain further intuition it is constructive to turn to a simulation, summarized in Table 1. The forth row is the frequency of budget revisions $[=0.5-(\tau / \alpha)]$. The fifth row is the expected budget error $E[b e]$, and the last row is the expected real expenditure, as a fraction of the "ideal" expenditure g. Note that the budgetary process yields an expected expenditure that is almost identical to the desirable one. This comes at a cost of frequent budget revisions and costly monitoring. The relative magnitude of the revision trigger and the initial budget adjustment depends critically on volatility. For example, if the range of the cost shock is $\pm 1 \%[\alpha=0.02]$, the contract is nominal and non-contingent. The initial allocation practically equals the target $g$, and the revision threshold is set at the upper limit of the range, such that the probability of budget revisions is zero. If the range of the cost shock increases to $\pm 10 \%$ [ $\alpha=0.2]$, the projected budget [i.e., the initial allocation $\mathrm{g}(1-\phi)]$ is $94.7 \%$ of the target allocation $g$, and the revision trigger is set at $-4.8 \%$. Hence, whenever the cost shock exceeds $-4.8 \%$, ministers can obtain a transfer that ensures that the ex-post expenditure equals $.9995[=\{1-\tau\}\{1-\phi\}]$ of the ideal expenditure $g$.

The ultimate effect of this arrangement is that the contract leads to expected real expenditure that deviates from the target $g$ by a second order magnitude. Further increase in volatility moves us towards full ex-post indexation, accomplished by reducing both the initial allocation and the revision trigger such that we approach continuous revisions, ensuring that the real expenditure is close to the expenditure target $g$. Thus, if the range of the cost shock is $\pm 50 \%[\alpha=1]$, the initial allocation drop to .72 of the ideal allocation $g$, and ministers obtain transfer whenever the cost shock exceeds - 38\%. The transfer guaranty real expenditure that practically equals the ideal expenditure. In these circumstances we are close to ex-post indexation -- it occurs with probability $88 \%$, leading to expected budget error of $52 \%$. 
Optimal policies depend on two costs: the state verification cost, and the cost of "mid-term" public funds. Figure 2 plots the dependency of the probability of budget revision (p) on the cost of public funds. Note that even if the cost of fund delivered in mid term is zero $[1+\lambda=0]$, costly state verification induces a budgetary process along the lines described above [although we reach full ex-post indexation at a lower volatility]. This case has a simple interpretation in our framework, as we allow so far only for idiosyncratic cost shocks. Hence, the treasury may manage a trust fund that provides insurance for the ministers, setting aside at the beginning of the budget cycle liquidity equals the expected budget revisions. If the costs of managing the trust fund are negligible, the cost of the midterm delivery of extra liquidity is zero, corresponding to $1+\lambda=0$. In a weak political system, however, liquid funds may induce rent seeking activities among ministers. Consequently, the treasury may refrain from managing a large precautionary fund, leading to a positive cost of managing the trust fund. ${ }^{14}$ Furthermore, if the treasury income is volatile due to Marco shocks, and if the country is facing credit constraints, managing such a trust fund may involve significant costs.

Figure 3 plots the dependency of the probability of budget revision (p) on the state verification costs. Note that even if the state verification cost is zero $[\mathrm{k}=0]$, costly mid-term funding induces a budgetary process along the lines described above [although we reach full expost indexation at a lower volatility]. Figure 4 considers the case where higher volatility increases verification costs. While positive dependence of verification cost on volatility reduces the frequency of budget revisions, it does not modify the overall results of our model. Note that volatility should exceed a threshold to induce budget revisions. Figures $2-4$ illustrates that the volatility threshold depends positively on the cost of public funds and the state verification cost.

14 Further discussion of this issue, see Hausmann, Powell and Rigobón (1992). 


\subsection{Endogenous Monitoring}

We assumed above that all budget revisions involve verification costs. In a more detailed model these costs are endogenously determined as part of the budgetary process. As was shown by Townsends (1988), even if monitoring costs are high, monitoring will be observed to prevent cost overstating. We turn now to an overview of such an extension.

Consider the case where ministers who request budget revisions should provide a detailed report of their unanticipated costs. The treasury monitors their requests randomly, at probability $p_{m}$. A minister that is detected "cheating" is denied the budget revision, and is penalized directly losing a fraction $\mathrm{c}$ of the planned budget, $c b^{p}, 0 \leq c \leq 1$. A risk neutral minister i who does not qualify for budget revision [i.e., a minister whose cost satisfies $\varepsilon_{i}<\tau$ ] has the incentive to cheat by reporting cost $\bar{\varepsilon}$ if $b_{i}^{p}\left[\frac{\bar{\varepsilon}-\tau}{1-\bar{\varepsilon}}\right]\left(1-p_{m}\right)>p_{m} c b^{p} .15$ Hence, detecting cheating requires setting the probability of monitoring high enough to reverse the above inequality. Consequently, the lowest monitoring probability that deters cheating is

$\tilde{p}_{m}=\frac{\left[\frac{\bar{\varepsilon}-\tau}{1-\bar{\varepsilon}}\right]}{\left[\frac{\bar{\varepsilon}-\tau}{1-\bar{\varepsilon}]}\right]+c}$. It equals to the ratio of the income gain from cheating over the sum of the income gain plus the direct penalty. If the direct penalty is nil, the monitoring probability is one, as was assumed in the model advanced in section 2.1 . Higher penalty $c$ reduces the probability of monitoring, saving recourses. More precisely, note that with effective random monitoring the loss function is

15 This condition states that the expected gain [which occurs if no monitoring takes place, with probability $\left(1-p_{m}\right)$ ] exceeds the expected loss [which occurs if monitoring takes place, with probability $\left.p_{m}\right]$. Note that if a minister is cheating, he/she would report the highest cost shock, as the expected gain increases with the cost report. 


$$
\begin{aligned}
& E[L]= \\
& \underset{\varepsilon}{\nu}\left[g_{i}[1-(1-\phi)(1-\varepsilon)]\right]^{2} \mathrm{f}(\varepsilon) \mathrm{d} \varepsilon+\left[\nu\left[g_{i}\{1-(1-\phi)(1-\tau)]\right]^{2}+\tilde{p}_{m} k\right] \int_{\tau}^{\bar{\varepsilon}} \mathrm{f}(\varepsilon) \mathrm{d} \varepsilon+ \\
& (1+\lambda) g_{i}(1-\phi) \int_{\tau}^{\bar{\varepsilon}} \frac{\varepsilon-\tau}{1-\varepsilon} \mathrm{f}(\varepsilon) \mathrm{d} \varepsilon
\end{aligned}
$$

The only difference between (6) and (6') is that random monitoring reduces the expected cost of verification. Hence, the qualitative results of random monitoring are similar to those associated with lower monitoring costs. More effective penalty (higher $c$ ) would increase the frequency of budget revisions, reducing the revision threshold and the planned budget. ${ }^{16}$ The magnitude of this penalty is determined by the political horizon of the administration, and by the relative strength of the center (as represented by the treasury) verses the competing interest groups (as represented by the various ministers). If the treasury cannot penalize opportunism by nominal cuts of the approved budget, the only remaining penalty is cutting the future budget. If the horizon of the administration is short, or if the constituencies represented by the mister are strong, the treasury may lack the capacity to penalize, implying $c=0$, leading to the analysis of Section 2.1 . A stronger center would be able to impose discipline by invoking more effective penalty (higher c), implying both lower realized costs of monitoring, as well as more frequent budget revisions.

16 For example, if $\mathrm{k}=2, \mathrm{~g}=100, v=1, \lambda=0.3, \alpha=0.3$, and $\mathrm{c}=0$ the probability of revision is $78.3 \%, \phi=0.08516, \tau=-0.085127$. If the penalty c raises to 0.4 , the probability of revision raises to $78.7 \%$, and $\phi=0.08565, \tau=-0.08596$. The probability of monitoring a minister that asks for budget revision drops from $100 \%$ to $41 \%$. Note that in this example allowing for random monitoring has rather small effects on the initial allocation and the revision trigger, but it has a relatively large impact on the expected monitoring cost, which drop from 1.56 $\%$ to $.64 \%$ of the budget. Allowing random monitoring has also the effect of reducing the volatility threshold associated with the switch from a nominal budget to a budgetary process that allows for revisions. 


\subsection{Volatility and budgetary discipline}

We conclude this section by noting that inflation and volatility change the budgetary process in a fundamental way. In the absence of inflation, the projected budget defines accurately both the real and the nominal budget. In an inflationary environment the projected budget defines only the initial condition in a complex budgetary process, where the ultimate allocation is the outcome of negotiations between the treasury and ministers. Hence, one of the costs of inflation is that nominal contracts lose their disciplining role in determining the real allocation. Instead, the economy shifts towards more costly arrangements, like ex-post indexation, where the discipline is accomplished by constant monitoring. For example, if $\mathrm{k}=2, \mathrm{~g}=100, v=1, \lambda=0.3$, in the absence of volatility the nominal budget leads to the optimal fiscal expenditure $\left(E\left[b^{a}\right]=100\right)$, without spending resources on monitoring. If the volatility rises to $\alpha=.3$ [i.e., the cost shocks are in the range of $\pm 15 \%$ ], the optimal budgetary process leads to frequent revisions $(\mathrm{p}=78.3 \%)$. In these circumstances enforcing the desirable real allocation necessitates spending (on average) $1.567 \%$ of the budget on monitoring. ${ }^{17}$ Hence, inflation increases the total budget outlay per minister from 100 to 101.49 . This qualitative result continues to hold even if the desired allocation $g$ depends negatively on the expected monitoring costs (as long as the dependence is not too elastic). ${ }^{18}$

17 It can be shown that in this case $E\left[b^{a}\right]=99.92$. The total budget outlay per minister is $99.92+1.567 \approx 101.49$.

18 For example, suppose that the target real expenditure is $g-a E[k]$, implying that the desired real expenditure drops by a fraction $a$ of the expected monitoring costs. It can be shown that for $\mathrm{a}=0.2$, (holding all other parameters intact), raising volatility form $\alpha=0$ to $\alpha=0.3$ increases the total real budget form 100 to 101.17. The main effect of allowing for the negative dependence of desired real expenditure on $E[k]$ is to reduce the projected budget (from 91.48 to 
Our model suggests that frequent budget revisions and tedious negotiations observed in inflationary environments should not be viewed as the causes of inflation. Instead, they represents the costly way with which the budgetary process copes with volatility. An attempt to deal with inflation should address the underlying fiscal deficiencies leading to inflation and instability, instead of attempting to restrict budget revisions. Evaluating the usefulness of budget revisions hinges on the relative strength of the treasury. Budget revisions are useful if the treasury is able to impose the discipline needed to grant revisions to ministers confronting large cost shocks. If the treasury is unable to impose this discipline (either because verification costs are too high, or because the treasury is unable to apply minister specific budgetary rules), it would be optimal to refrain from budget revisions. ${ }^{19}$ Our results can be restated in terms of the "rules versus discretion" terminology. A "rule" prohibiting budget revisions is preferable if the treasury is weak (or if the costs of monitoring are high), a "discretion" in the form of budget revisions is preferable if the treasury is relatively strong.

91.20), leading to expected real expenditure of $E\left[b^{a}\right]=99.61$. It can be shown that the changes in other parameters are of second order magnitude.

19 This would be the case if verification costs are large enough to induce a corner solution where the budgetary contract is nominal. 


\section{Budgetary Rules. Unexpected Inflation And Public Funds Shocks}

A limitation of our previous discussion is that we assumed away macro shocks, and focused on the degree to which the treasury insures the ministers against idiosyncratic shocks. The propose of this section is to show that our pervious results continue to hold in the presence of macro shocks. We consider now the case where the inflation is stochastic, and where the cost of public funds may vary systematically with inflation. Specifically, we modify section 2 by assuming that the realized inflation may differ from the anticipated $\Pi_{0}$ by a random term, $\delta_{t}$. We continue to denote the planned real budget by $b_{i}^{p}, b_{i}^{p}=\frac{B_{i}}{P_{-1} \exp \left(\Pi_{0}\right)}$. Thus, the real budget in the absence of budget revisions is (see the Appendix for a detailed description of the assumed stochastic structure)

$$
b_{i}=b_{i}^{p}\left[1-\delta-\varepsilon_{i}\right]
$$

where $\varepsilon_{i}$ is the idiosyncratic cost shock affecting activity $\mathrm{i}$ whose mean across ministers is zero, and $\delta$ is the inflation surprise. To simplify exposition, we focus on the case where both the inflation and the cost shocks are uniform distributed. We assume that the variances depend positively on the expected inflation, $\varepsilon_{i} \in\left[-0.5 \alpha \Pi_{o}, 0.5 \alpha \Pi_{o}\right] ; \delta \in\left[-0.5 \beta \Pi_{o}, 0.5 \beta \Pi_{0}\right]$ with $0 \leq \alpha, \beta \leq 2$.

Hence, higher expected inflation increases the variances of both inflation surprises and cost shocks, where $\alpha, \beta$ measure the volatility responsiveness to inflation. The main difference between the present case and section 2 is that we allow now for macroeconomic risk associated with inflation volatility. Note that developing countries frequently use the inflation tax as the residual means of taxation. In these circumstances adverse fiscal shocks [induce, for example, by a drop in export revenue, recessions, etc.] tend to increase inflation. 20 Hence, one may expect

20 Further discussion of this issue, see Edwards and Tabellini (1991), Calvo and Guidotti (1993), and Guidotti and Vegh (1993). 
that the cost of public funds delivered in mid term is positively correlated with inflation surprises. For example, suppose that the cost of pubic funds is:

$$
\lambda_{t}=\left(1+\lambda_{0}\right) \exp (n \delta) ; \quad n \geq 0
$$

If the cost of public funds is unrelated to inflation, $n=0$. Higher $n$ indicates greater fiscal fragility, where the cost of funds vary more with the underlying macro shocks inducing the inflation shocks.

Similarly to Section 2, we assume that the planned budget is set by the condition $b_{i}^{p}=g_{i}[1-\phi]$, where $\phi$ is a policy instrument, and $b_{i}^{p}$ is the real expenditure if the random shocks are zero. ${ }^{21}$ We consider now two cases. The first is an economy where both the inflation shock and the cost specific shock are each minister's private information, reveled to the treasury at a cost k. The second is an economy where the inflation shock is known to all, whereas the cost specific shock is each minister's private inflation, reveled to the treasury at a cost $\mathbf{k}$.

\subsection{Budgetary process when inflation and cost shocks are private information.}

The treasury is assumed to follow a modified trigger policy, generalizing equation (2):

$$
b_{i}^{a}=\left\{\begin{array}{lll}
b_{i}^{p}\left[1-\left(\varepsilon_{i}+\delta\right)\right] & \text { if } \quad \tau>\varepsilon_{i}+\delta \\
b_{i}^{p}[1-\tau] & \text { if } \tau \leq \varepsilon_{i}+\delta
\end{array} .\right.
$$

Hence, if the budget is revised, the minister obtains a nominal transfer of [see the Appendix for derivation]

21 Thus, the treasury allocates at the beginning of the period nominal budget $B_{i}^{p}=g_{i}(1-\phi) P_{0}$. 
(3') $\Delta B_{i}=P_{0} b_{i}^{p} \frac{\varepsilon_{i}+\delta-\tau}{1-\varepsilon_{i}-\delta} \cong P_{0} b_{i}^{p}\left[\varepsilon_{i}+\delta-\tau\right]$.

The treasury is setting the budget contract in an attempt to minimize the loss function (4). Similarly to section 2, one can show that claims 1-2 continues to apply. To appreciate the new aspects introduced by macro uncertainty we turn to Table 2, reporting a simulation. Note that for a given $n$ [i.e., for a given responsiveness of the cost of public funds to surprised inflation] the results of section 2 continue to hold - higher volatility reduces the initial allocation and the revision threshold, increasing the frequency of revisions. A higher responsiveness of the cost of public funds to inflation shocks dampens the use of budget revisions - for a given volatility we observe higher initial allocation and higher revision threshold, and lower probability of budget revision. For high enough volatility we approach a corner solution, where we observe ex-post indexation. This is accomplished by an initial allocation and a revision threshold that induces continues budget revisions. For example, if $n=0$ and the range of the cost shock is $\pm 10 \%$ (corresponding to $\Pi_{0}=$ 0.4 ), the initial allocation falls short of the "ideal" allocation by $8.2 \%$, and the revision threshold is set at $-8.3 \%$, implying that in most states of nature the treasury transfers extra funds to ensure expost expenditure that practically equals the ideal expenditure. 22 This form of ex-post indexation is the best that can be accomplished in the present contract, leading to an average budgetary error of 0.087 .23 Fiscal fragility reduces the probability of budget revisions, and moves the contract away

22 More precisely, budget revisions lead to real expenditure of $(1-0.082)(1-[-0.083]) g \approx g$.

23 We obtain this figure by calculating the expected nominal transfer associated with the budget revision, which equals $B_{i}^{p}\left[\int_{-0.5 \alpha \Pi_{0}}^{0.5 \alpha \Pi_{0}+\tau}\left\{\int_{-0.5 \alpha \Pi_{0}}^{+0.5 \alpha \Pi_{0}} \frac{\varepsilon+\delta-\tau}{1-[\varepsilon+\delta]} d \varepsilon\right\} d \delta\right] \frac{1}{\left[\alpha \Pi_{0}\right]^{2}}+B_{i}^{p}\left[\int_{0.5 \alpha \Pi_{0}+\tau}^{0.5 \alpha \Pi_{0}}\left\{\int_{-0.5 \alpha \Pi_{0}}^{+0.5 \alpha \Pi_{0}} \frac{\varepsilon+\delta-\tau}{1-[\varepsilon+\delta]} d \varepsilon\right\} d \delta\right] \frac{1}{\left[\alpha \Pi_{0}\right]^{2}}$

[where $B_{i}^{p}$ stands for the projected nominal budget]. 
from ex-post indexation. In the above example, if $n=25$ (instead of 0 ), the probability of budget revisions drop from $93 \%$ to $64 \%$.

\subsection{Budgetary process with observable inflation}

We consider now the case where inflation is observed to all, whereas the cost shock is each minister's private information (revealed to the treasury at a cost $\mathbf{k}$ ). Observable inflation adds a new policy instrument, as it allows the treasury to index the budget to the observed inflation shock. While (by assumption) implementing this indexation does not involve verification costs, it is not cost free as it involves mid term delivery of funds. We denote by 1 - $\rho$ the degree of indexation adapted by the treasury, and continue to assume that (11) determines the cost of funds delivered in mid term. The partial indexation policy modifies the design of budget revisions. We assume that budget revisions are given by a trigger rule:

$\left(12^{\prime}\right) \quad b_{i}^{a}=\left\{\begin{array}{llr}b_{i}^{p}\left[1-\left(\varepsilon_{i}+\rho \delta\right)\right] & \text { if } \quad \tau>\varepsilon_{i} \\ & & \\ b_{i}^{p}[1-(\tau+\rho \delta)] & \text { if } \quad \tau \leq \varepsilon_{i}\end{array}\right.$

With observable inflation the treasury designs polices that distinguish between the observed inflation and the unobserved cost shock. The partial indexation alleviates a fraction of 1 - $\rho$ of the common inflation shock, whereas the budget revision alleviates large specific cost shocks. Comparison of $\left(12^{\prime}\right)$ to (12) reveals that when inflation is unobserved, the policy maker designs a revision rule that lumps the sum of inflation and the cost shock into a composite shock $\left(=\varepsilon_{i}+\delta\right)$, whereas if the inflation shock is known, $\varepsilon_{i}$ and $\delta$ are treated differentially.

The policy maker determines three policy instruments: $\rho, \phi$, and $\tau$. Direct optimization reveals that complete indexation to inflation shocks is optimal when the cost of public funds is independent from inflation [i.e., $n=0$ implies $\rho=0$ ]. Greater fiscal fragility (i.e., a higher $n$ ) 
reduces the indexation to inflation shocks, as well as the use of budgetary revisions. Table 3 summarizing a simulation. As in Section 3.1, volatility increases the probability of budget revisions. Fiscal fragility increases the costs of indexation to unexpected inflation, reducing thereby optimal indexation. ${ }^{24}$ Similarly, higher volatility implies that the cost of indexation to the inflation shock is higher, reducing thereby the degree of indexation.

24 Note that if inflation is not correlated with public funds cost shocks, budgets will be fully indexed to the inflation shock. In this case the optimal contract leads to $\phi$ and $\tau$ identical to the one analyzed in Section 2, where inflation was assumed to be non-stochastic. 


\section{Inflation And Budgetary Errors - Empirical Investigation}

We turn now to test some of the predictions of our model. Specifically, our model suggests that higher inflation (and the induced higher volatility) increases the budget error. We test this prediction using a panel data from 12 Latin American countries. A direct test of our model requires detailed information of cost shocks affecting various sectors. Unfortunately, the only available information at our disposition is the inflation and the budget error. The positive correlation between inflation and the volatility of relative prices identified in various studies motives us to study the implications of inflation on budgetary errors.

Regression 1, Table 4 summarizes the results for the case where the dependent variable is the budget error [be, defined in Section 2], and the explanatory variables are the inflation and a constant. Our results indicate that higher inflation increases the budget error (and this effect is highly significant). ${ }^{25}$ Regression 2 , Table 4 summarizes the case where we decompose inflation into the expected and the unexpected components. The decomposition is accomplished by fitting an $A R(1)$ process for the inflation of each country, using the fitted equation to obtain the "expected" and the "unexpected" components of inflation. Table 4 reveals that both the expected and the unexpected inflation increase the budget error. It suggests that the pattern exhibited by Venezuela in Figure 1 is shared by the other countries -- budgetary surprises are positively correlated with inflation, and there is a bias for positive budgetary errors in inflationary economies.

25 Note that the constant term is insignificant. We tested a non-linear [quadratic] dependency of the budget error on inflation, finding that the quadratic term is insignificant. We also tested a specification that allowed for country specific effects, finding that adding country specific dummies does not modify the qualitative results (only two country specific effects turned out to be marginally significant). 


\section{Concluding remarks}

We close the paper with a discussion of limitations and possible extensions.

In the paper we assumed that the cost shock does not change the desirable real expenditure. This assumption can be relaxed, to recognize the possibility of a negative dependency of the desired real expenditure on costs. It can be shown that as long as the demand for fiscal expenditure is inelastic, our qualitative results continue to hold. The results are significantly modified if the demand for fiscal services is price elastic. For example, with a unitary price elasticity a nominal contract is optimal, as the total nominal expenditure needed to meet the expenditure target is constant. More generally, the budgetary process would be closer to an expost indexation for services the demand for which is inelastic, and to a nominal contract for services the demand for which is elastic.

While the paper dealt with inflation, the fundamental issue addressed above is volatility -the paper's results are applicable even in the absence of inflation, as long as relative prices are volatile. Our model described conditions leading to budget revisions as the optimal response to volatility. In deriving these results we assumed a strong treasury -- it is able to monitor the ministers, and to invoke budgetary revisions tailored to the specific shocks of each minister. If the treasury is not strong (or if the costs of monitoring are too high), our model implies that prohibiting budget revision is optimal. Hence, a key factor determining the design of budgets is the strength and the competence of the treasury. 


\section{APPENDIX}

The purpose of this Appendix is the review the proofs of Claims 1-2, and equations (10) and ( $\left.3^{\prime}\right)$.

\section{Claim 1:}

a. The conditions for an internal equilibrium are

(A1) $E[L]_{\tau}^{\prime}=(1-\phi)\left[2 v\left[g_{i}\right]^{2}\{1-(1-\phi)(1-\tau)\}\right] \int_{\tau}^{\bar{\varepsilon}} \mathrm{f}(\varepsilon) \mathrm{d} \varepsilon-g_{i}(1-\phi)(1+\lambda) \int_{\tau}^{\bar{\varepsilon}} \frac{\mathrm{f}(\varepsilon)}{1-\varepsilon} \mathrm{d} \varepsilon-k f(\tau)=0$

(A2)

$$
E[L]_{\phi}=-2 v \int_{\varepsilon}^{\tau}\left[g_{i}\right]^{2}\{1-(1-\phi)(1-\varepsilon)\}(1-\varepsilon) \mathrm{f}(\varepsilon) \mathrm{d} \varepsilon
$$

$$
-2(1-\tau) \mathcal{V}\left[g_{i}\right]^{2}\{1-(1-\phi)(1-\tau)\} \int_{\tau}^{\bar{\varepsilon}} \mathrm{f}(\varepsilon) \mathrm{d} \varepsilon+(1+\lambda) g_{i} \int_{\tau}^{\bar{\varepsilon}} \frac{\varepsilon-\tau}{1-\varepsilon} \mathrm{f}(\varepsilon) \mathrm{d} \varepsilon=0
$$

(A3) $E[L]_{\phi \tau}^{\prime \prime}=2 v\left[g_{i}\right]^{2}\{1-2(1-\phi)(1-\tau)\} \int_{\tau}^{\bar{\varepsilon}} \mathrm{f}(\varepsilon) \mathrm{d} \varepsilon-(1+\lambda) g_{i} \int_{\tau}^{\bar{\varepsilon}} \frac{1}{1-\varepsilon} \mathrm{f}(\varepsilon) \mathrm{d} \varepsilon$

where the second order conditions are

$$
\begin{aligned}
& E[L]_{\tau \tau}^{\prime \prime}>0 ; \quad E[L]_{\phi \phi}^{\prime \prime}>0 ; \\
& D=E[L]_{\tau \tau}^{\prime \prime} E[L]_{\phi \phi}^{\prime \prime}-\left[E[L]_{\tau \phi}^{\prime \prime}\right]^{2}>0 .
\end{aligned}
$$

From (A1) and (A2) we infer that

(A4)

$E[L]_{\tau k}^{\prime \prime}=-f(\tau), \quad E[L]_{\phi k}^{\prime \prime}=0, \quad E[L]_{\tau \lambda}^{\prime \prime}=-(1-\phi) g_{i} \int_{\tau}^{\bar{\varepsilon}} \frac{1}{1-\varepsilon} \mathrm{f}(\varepsilon) \mathrm{d} \varepsilon=0, \quad E[L]_{\phi \lambda}^{\prime \prime}=g_{i} \int_{\tau}^{\bar{\varepsilon}} \frac{\varepsilon-\tau}{1-\varepsilon} \mathrm{f}(\varepsilon) \mathrm{d} \varepsilon$.

Applying Cramer's rule we infer that

(A5) $\quad \operatorname{sign}\left[\frac{\partial \tau}{\partial k}\right]=\operatorname{sign}\left|\begin{array}{cc}E_{\phi \phi}^{\prime \prime} & 0 \\ E_{\tau \phi}^{\prime \prime} & f(\tau)\end{array}\right|>0$; .

and 
(A6) $\operatorname{sign}\left[\frac{\partial \phi}{\partial k}\right]=\operatorname{sign}\left|\begin{array}{ll}0 & E_{\tau \phi}^{\prime \prime} \\ f(\tau) & E_{\tau \tau}^{\prime \prime}\end{array}\right|=-\operatorname{sign}\left[f(\tau) E_{\tau \phi}^{\prime \prime}\right]=-\operatorname{sign}\left[E_{\tau \phi}^{\prime \prime}\right]$

Inspection of (A3) reveals that a sufficient condition for $E^{\prime \prime}<0$ [and thus for $\left.\operatorname{sign}\left[\frac{\partial \phi}{\partial k}\right]>0\right]$ is that $1<2(1-\phi)(1-\tau)$. The last inequality holds as long as the threshold level exceeds half of the ideal expenditure, a condition that is more than likely to be met.

To infer the sign of $\operatorname{sign}\left[\frac{\partial \tau}{\partial \lambda}\right]$ we note that

(A7)

$$
\operatorname{sign}\left[\frac{\partial \tau}{\partial \lambda}\right]=\operatorname{sign}\left|\begin{array}{cc}
E_{\phi \phi}^{\prime \prime} & g_{i} \int_{\tau}^{\bar{\varepsilon}} \frac{\varepsilon-\tau}{1-\varepsilon} \mathrm{f}(\varepsilon) \mathrm{d} \varepsilon \\
E_{\tau \phi}^{\prime \prime} & -(1-\phi) g_{i} \int_{\tau}^{\bar{\varepsilon}} \frac{1}{1-\varepsilon} \mathrm{f}(\varepsilon) \mathrm{d} \varepsilon
\end{array}\right|
$$

To infer the sign, we substitute the values of the second order terms and collect the various terms. Applying to the resultant equation the fact that $1>(1-\phi)(1-\tau)$ [which follows from (A1)] we infer that $\operatorname{sign}\left[\frac{\partial \tau}{\partial \lambda}\right]>0$.

b. Note that in the absence of budget revisions $\tau=\bar{\varepsilon}$, and the projected budget is determined by (A2):

$$
\left(\mathrm{A} 2^{\prime}\right) \quad E[L]_{\phi}=-2 v \int_{\underline{\varepsilon}}^{\bar{\varepsilon}}\left[g_{i}\right]^{2}\{1-(1-\phi)(1-\varepsilon)\}(1-\varepsilon) \mathrm{f}(\varepsilon) \mathrm{d} \varepsilon=0,
$$

which implies that

$$
\text { (A8) } 1-\phi=\frac{1}{\int_{\underline{\varepsilon}}^{\varepsilon}(1-\varepsilon)^{2} \mathrm{f}(\varepsilon) \mathrm{d} \varepsilon}=\frac{1}{1+\int_{\underline{\varepsilon}}^{\bar{\varepsilon}} \varepsilon^{2} \mathrm{f}(\varepsilon) \mathrm{d} \varepsilon}=\frac{1}{1+V_{\varepsilon}}
$$

Consequently, $\phi=\frac{V_{\varepsilon}}{1+V_{\varepsilon}}$ 
c. Note that with full ex-post indexation, $\tau=\underline{\varepsilon}$. Thus, the loss function is reduced to

$$
E[L]=\left[v\left[g_{i}(1-(1-\phi)(1-\underline{\varepsilon})]\right]^{2}+k\right] 1+(1+\lambda) g_{i}(1-\phi) \int_{\underline{\varepsilon}}^{\bar{\varepsilon}} \frac{\bar{\varepsilon}-\underline{\varepsilon}_{f}}{1-\varepsilon}(\varepsilon) \mathrm{d} \varepsilon .
$$

The optimal allocation $\underline{\phi}$ reported in Claim $1 \mathrm{c}$ is obtained by minimizing $\left(6^{\prime}\right)$ with respect to $\phi$.

\section{Claim 2}

Note that

$$
\begin{aligned}
& \frac{d E[b e]}{d \alpha}=\frac{1}{2 \alpha} \frac{0.5 \alpha-\tau}{1-0.5 \alpha}-\int_{\tau}^{0.5 \alpha} \frac{\varepsilon_{i}-\tau}{1-\varepsilon_{i}} \frac{1}{\alpha^{2}} \mathrm{~d} \varepsilon+\frac{\partial E[b e]}{\partial \tau} \frac{\partial \tau}{\partial \alpha}= \\
& \frac{1}{2 \alpha} \frac{0.5 \alpha-\tau}{1-0.5 \alpha}-\frac{(1-\tau) \ln \frac{1-\tau}{1-0.5 \alpha}-(0.5 \alpha-\tau)}{\alpha^{2}}-\left[\int_{\tau}^{0.5 \alpha} \frac{1}{1-\varepsilon_{i}} \frac{1}{\alpha} \mathrm{d} \varepsilon\right] \frac{\partial \tau}{\partial \alpha}= \\
& \frac{1}{\alpha^{2}}\left[\frac{1-\tau}{1-0.5 \alpha}-(1-\tau) \ln \frac{1-\tau}{1-0.5 \alpha}-1\right]-\left[\int_{\tau}^{0.5 \alpha} \frac{1}{1-\varepsilon_{i}} \frac{1}{\alpha} \mathrm{d} \varepsilon\right] \frac{\partial \tau}{\partial \alpha}
\end{aligned}
$$

The last term is positive [recall that $\left.\frac{\partial \tau}{\partial \alpha}<0\right]$.

By inspecting the derivative of $\frac{1-\tau}{1-0.5 \alpha}-(1-\tau) \ln \frac{1-\tau}{1-0.5 \alpha}-1$ with respect to $\alpha$ we infer that $\frac{1-\tau}{1-0.5 \alpha}-(1-\tau) \ln \frac{1-\tau}{1-0.5 \alpha}-1>0$ for $0.5 \alpha>\tau$, concluding our proof. ${ }^{26}$

26 Note that $\frac{1-\tau}{1-0.5 \alpha}-(1-\tau) \ln \frac{1-\tau}{1-0.5 \alpha}-1=0$ for $0.5 \alpha=\tau$, and that $\operatorname{sign} \frac{\partial\left[\frac{1-\tau}{1-0.5 \alpha}-(1-\tau) \ln \frac{1-\tau}{1-0.5 \alpha}-1\right]}{\partial \alpha}>0$ for $1>\tau>0$. Combining these facts it follows that $\frac{1-\tau}{1-0.5 \alpha}-(1-\tau) \ln \frac{1-\tau}{1-0.5 \alpha}-1>0$ for $0.5 \alpha>\tau$. 


\section{Equation (10)}

We describe now the stochastic structure leading to the specification used in Section 3. Let the price of activity $i$ at time $t$ be $P_{-1} \exp \left[\Psi_{i}\right]\left(\Psi_{i}\right.$ is approximately one plus the inflation rate measured in terms of activity $i)$. We assume that the expected value of $\exp \left[\Psi_{i}\right]$ is the same for all activities, and denote it by $\exp \left[\Pi_{0}\right]$.

Define $\psi_{i}=1-\exp \left[\Pi_{0}-\Psi_{i}\right]$, measuring (approximately) the unanticipated inflation in terms of good $i$. Let $\delta$ measure the inflation shock common to all activities, and let $\varepsilon_{i}$ stand for the cost shock affecting activity i. Hence, $\psi_{i}=\delta+\varepsilon_{i}$. We assume that $\varepsilon_{i}$ are i.i.d. distributed across ministers. Applying this notation we infer that $P_{-1} \exp \left[\Psi_{i}\right]=\frac{P_{-1} \exp \left[\Pi_{0}\right]}{\exp \left[\Pi_{0}-\Psi_{i}\right]}=\frac{P_{0}}{1-\left\{\varepsilon_{i}+\delta\right\}}$ where $P_{0}=P_{-1} \exp \left[\Pi_{0}\right]$ is the price level if all shocks are zero. Consequently, $b_{i}=\frac{B_{i}^{p}}{P_{-1} \exp \left[\Psi_{i}\right]}=\frac{B_{i}^{p}}{P_{o}}\left[1-\delta-\varepsilon_{i}\right]=b_{i}^{p}\left[1-\delta-\varepsilon_{i}\right]$

\section{Equation (3')}

To ensure real expenditure of $b_{i}^{P}[1-\tau]$ the minister needs a nominal budget of $b_{i}^{p}[1-\tau] P_{-1} \exp \left[\Psi_{i}\right]=b_{i}^{p}[1-\tau] P_{-1} \exp \left[\Pi_{0}\right] \exp \left[\Psi_{i}-\Pi_{0}\right]=B_{i}^{p} \frac{1-\tau}{1-\left\{\delta+\varepsilon_{i}\right\}}$

Consequently, the needed nominal transfer is $\Delta B_{i}=B_{i}^{p}\left[\frac{1-\tau}{1-\varepsilon_{i}-\delta}-1\right]=B_{i}^{p}\left[\frac{\varepsilon_{i}+\delta-\tau}{1-\varepsilon_{i}-\delta}\right]$. 


\section{References}

Aizenman, Joshua, 1984, "Optimal Wage Re-negotiation in a Closed and Open Economy," Journal of Monetary Economics, 13, pp. 251-262.

Alesina, Alberto; Ricardo, Hausmann, Rudolf Hommes, and Ernesto Stein, 1995, "Budgetary Institutions and Fiscal Performance in Latin America," manuscript, the Inter-American Development Bank.

Cukierman, Alex, 1984, "Inflation, Stagflation, Relative Prices and Imperfect Information," Cambridge, Cambridge University Press.

Calvo, Guillermo A. and Graciela L. Kaminsky, 1991, "Debt relief and debt rescheduling," Journal of Development Economics 36, pp. 5-36.

Calvo, Guillermo A. and Pablo E. Guidotti, 1993, "On the Flexibility of Monetary Policy: The Case of the Optimal Inflation Tax," Review of Economic Studies; 60(3), pp. 667-87.

Cantor, Richard M. 1988, "Work Effort and Contract Length," Economica; 55, pp. 343-53. Diamond, D. , 1984, Financial intermediation and delegated monitoring, Review of Economic Studies 51, pp. 393-414.

Edwards, Sebastian and Guido Tabellini, 1991, "Explaining Fiscal Policies and Inflation in Developing Countries," Journal of International Money and Finance; 10(0), pp S16-48.

Fundenberg, Drew and Jean Tirole, 1991, Game Theory, MIT Press, Cambridge, Massachusetts. Guidotti, PabloE.; Vegh, Carlos, A. 1993, "The Optimal Inflation Tax When Money Reduces Transactions Costs: A Reconsideration," Journal of MonetaryEconomics 31,pp. 189-205. Hausmann, Ricardo; Andrew Powell and Roberto Rigobón. 1992. "An optimal spending rule facing oil income uncertainty (Venezuela)," in External Shocks and Stabilization Mechanisms, (E. Engel and P. Meller, eds.), IDB, Washington.

Townsends, Robert, M., 1979, "Optimal contracts and competitive markets with costly state verification," Journal of Economic Theory 21, pp. 265-293. 1988, "Information constrained insurance: the revelation principle extended,"

Journal of Monetary Economics 21, (2/3), pp. 411-450 
Table 1

Cost volatility

$\mathrm{g}=100, \mathrm{k}=0.5, \lambda=0.3, \mathrm{v}=1$

\begin{tabular}{c|c|c|c|c|c|c|c|}
\hline $\begin{array}{c}\text { Volatility } \\
\alpha\end{array}$ & 0.02 & 0.05 & 0.1 & 0.2 & 0.3 & 0.4 & 1 \\
\hline $\begin{array}{c}\text { Projected } \\
\text { revenue } \phi\end{array}$ & 0 & 0.0051 & 0.02 & 0.053 & 0.086 & 0.11 & 0.28 \\
\hline $\begin{array}{c}\text { Revision } \\
\text { threshold } \tau\end{array}$ & 0.01 & 0.0026 & -0.013 & -0.048 & -0.087 & -0.126 & -0.38 \\
\hline $\begin{array}{c}\text { Revision } \\
\text { probability }\end{array}$ & 0 & 44 & 62 & 74 & 79 & 81 & 88 \\
\hline $\begin{array}{c}\text { budget } \\
\text { error be }\end{array}$ & 0 & 0.001 & 0.019 & 0.055 & 0.1 & 0.15 & 0.525 \\
\hline $\begin{array}{c}\text { expected } \\
\text { budget /g }\end{array}$ & 1 & 0.99988 & 0.99975 & 0.9995 & 0.9992 & 0.9990 & 0.997 \\
\hline
\end{tabular}

Table 2

Random and unobservable inflation and specific cost shocks

\begin{tabular}{|c|c|c|c|c|c|c|} 
& \multicolumn{3}{c}{$\mathrm{g}=100, \mathrm{k}=0.5, \lambda_{0}=0.3, v=1, \alpha=\beta=0.5$} \\
$\mathrm{n}=\mathbf{0}$ & 0.2 & 0.4 & 0.1 & 0.2 & 0.4 \\
\hline $\begin{array}{c}\text { Expected inflation } \\
\Pi_{0}\end{array}$ & 0.1 & 0.2 & & & & \\
\hline $\begin{array}{c}\text { Volatility } \\
\alpha \Pi_{0}\end{array}$ & 0.05 & 0.1 & 0.2 & 0.05 & 0.1 & 0.2 \\
\hline $\begin{array}{c}\text { Projected revenue } \\
\phi\end{array}$ & 0.01 & 0.033 & 0.082 & 0.007 & 0.024 & 0.049 \\
\hline $\begin{array}{c}\text { Revision threshold } \\
\tau\end{array}$ & -0.002 & -0.027 & -0.083 & 0.002 & -0.014 & -0.028 \\
\hline $\begin{array}{c}\text { Revision } \\
\text { probability \% }\end{array}$ & 54 & 77 & 93 & 45 & 63 & 64 \\
\hline
\end{tabular}


Table 3

Random and observable inflation, unobservable random specific cost shocks

\begin{tabular}{|c|c|c|c|c|c|c|}
\multicolumn{5}{|c}{$\mathrm{g}=100, \mathrm{k}=0.5, \lambda_{0}=0.3, v=1, \alpha=\beta=0.5$} \\
$\mathrm{n}=0$ \\
$\begin{array}{c}\text { Expected inflation } \\
\Pi_{0}\end{array}$ & 0.1 & 0.2 & 0.4 & 0.1 & 0.2 & 0.4 \\
\hline $\begin{array}{c}\text { Volatility } \\
\alpha \Pi_{0}\end{array}$ & 0.05 & 0.1 & 0.2 & 0.05 & 0.1 & 0.2 \\
\hline $\begin{array}{c}\text { Projected revenue } \\
\phi\end{array}$ & 0.0051 & 0.02 & 0.053 & 0.0048 & 0.017 & 0.038 \\
\hline $\begin{array}{c}\text { Revision threshold } \\
\tau\end{array}$ & 0.0026 & -0.013 & -0.048 & 0.003 & -0.009 & -0.024 \\
\hline $\begin{array}{c}\text { Revision } \\
\text { probability \% } \\
\text { Indexation } \\
1-\rho\end{array}$ & 44 & 62 & 74 & 43 & 59 & 62 \\
\hline
\end{tabular}

Table 4

Budgetary error and inflation: panel data from 12 Latin American countries 27

\begin{tabular}{|c|c|c|}
\hline & (1) & (2) \\
\hline Constant & $\begin{array}{c}-0.217 \\
(-1.556)\end{array}$ & $\begin{array}{l}-0.20 \\
(-1.4)\end{array}$ \\
\hline Inflation/[1+ Inflation] & $\begin{array}{r}2.47 \\
(5.85) \\
\end{array}$ & - \\
\hline Expected inflation/[1+ Inflation] & - & $\begin{array}{r}2.66 \\
(6.01) \\
\end{array}$ \\
\hline $\begin{array}{l}\text { Unexpected inflation/ } \\
{[1+\text { Inflation }]}\end{array}$ & 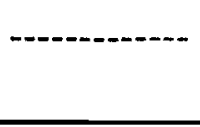 & $\begin{array}{r}2.81 \\
(6.14) \\
\end{array}$ \\
\hline Adjusted $\mathrm{R}^{2}$ & .125 & .14 \\
\hline
\end{tabular}

Dependent variable: budget's deviation from approved, $t$ statistics are in parentheses. Data source: data collected at the IDB for Alesina, Hausmann, Hommes and Stein (1995) 


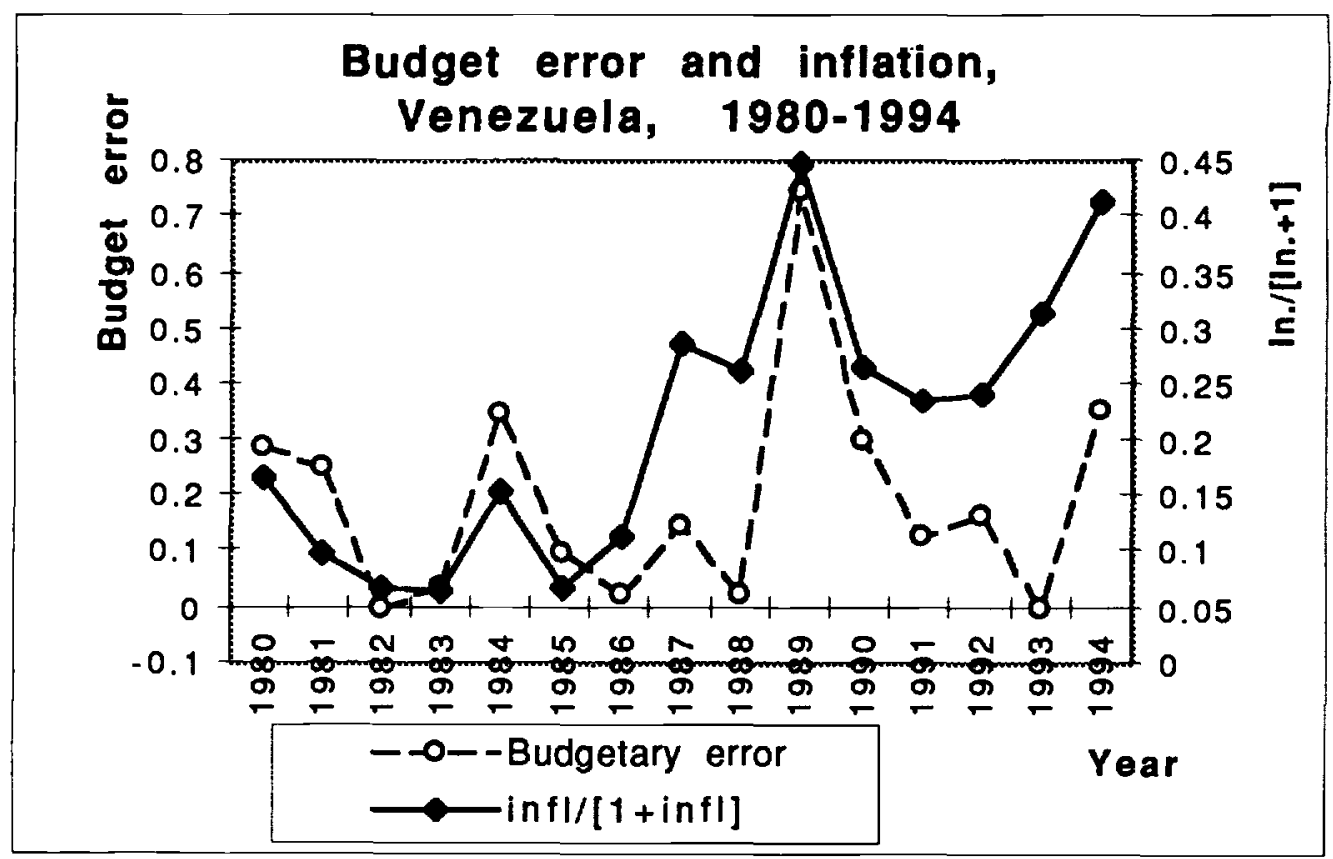

(a)

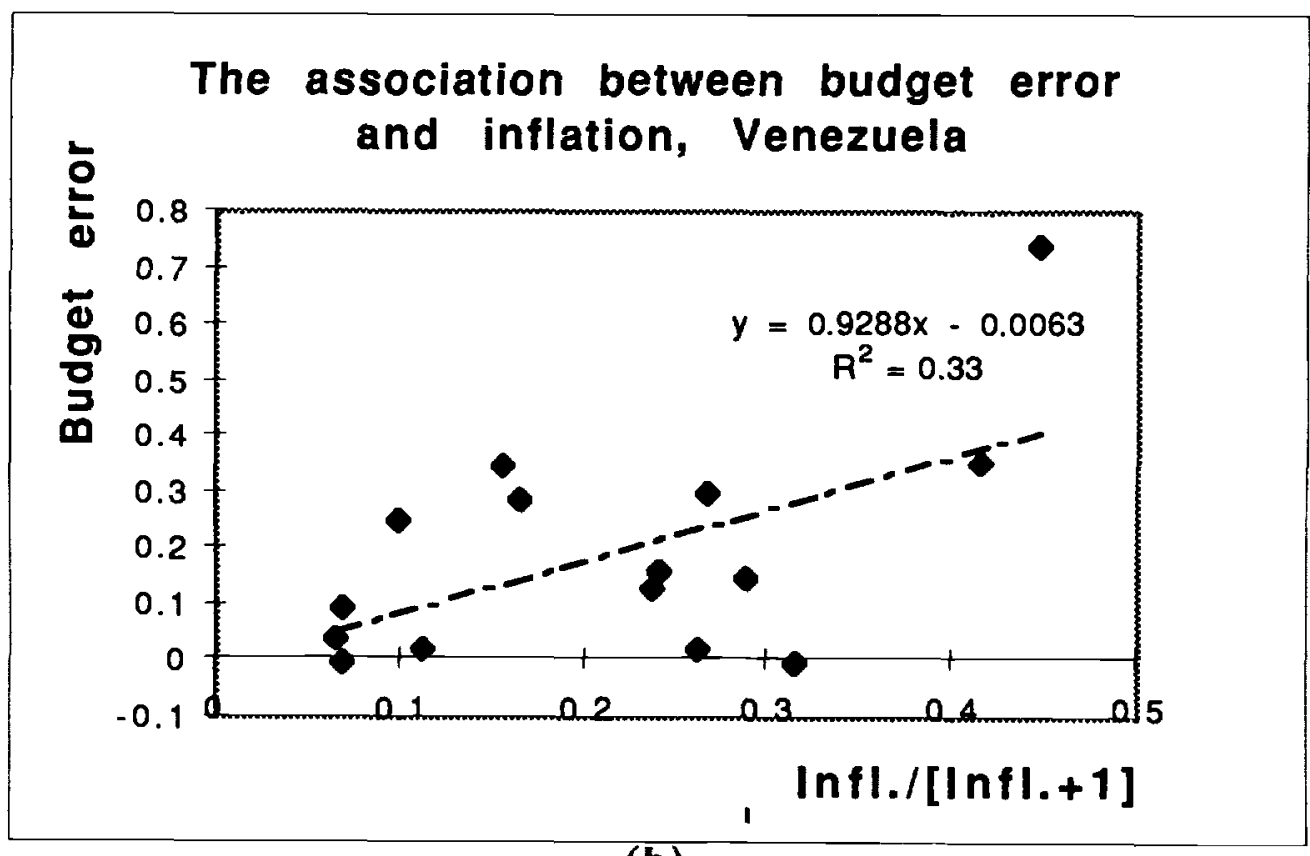

(b)

Figure 1

Budget errors and inflation, Venezuela, 1980-1994 


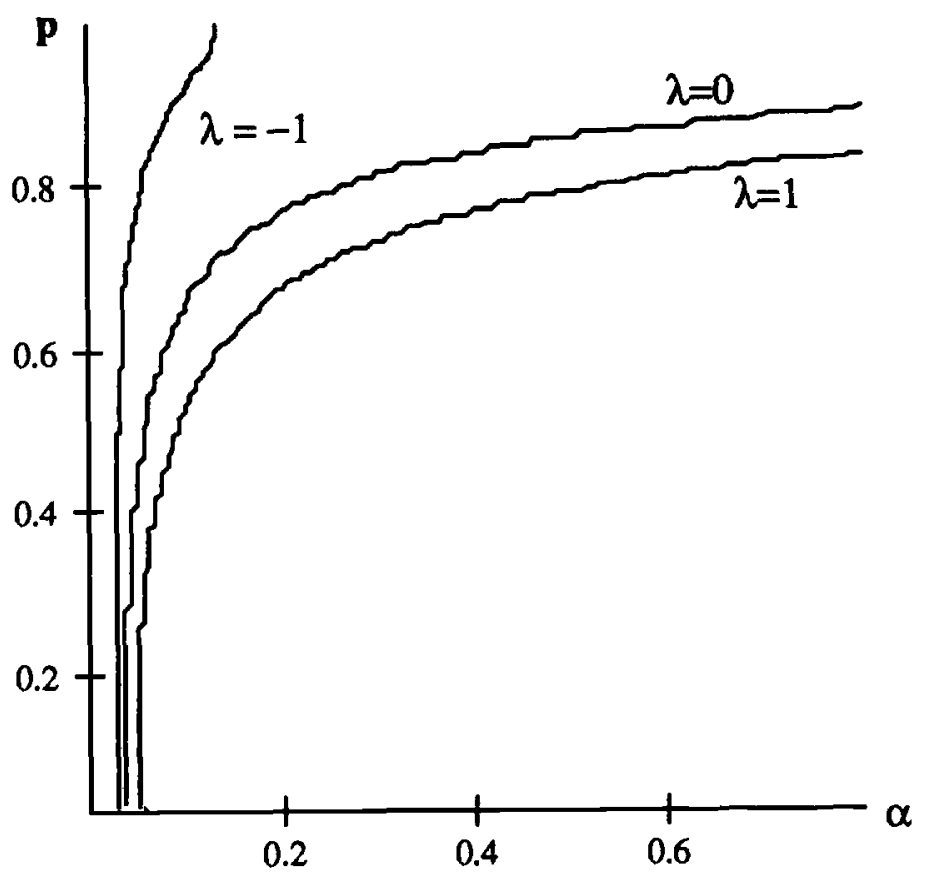

Figure 2

Budget revision probability $(p)$ and the cost of public funds $(\lambda)$

Drawn for $\mathrm{g}=100, \mathrm{k}=1, v=1$. 


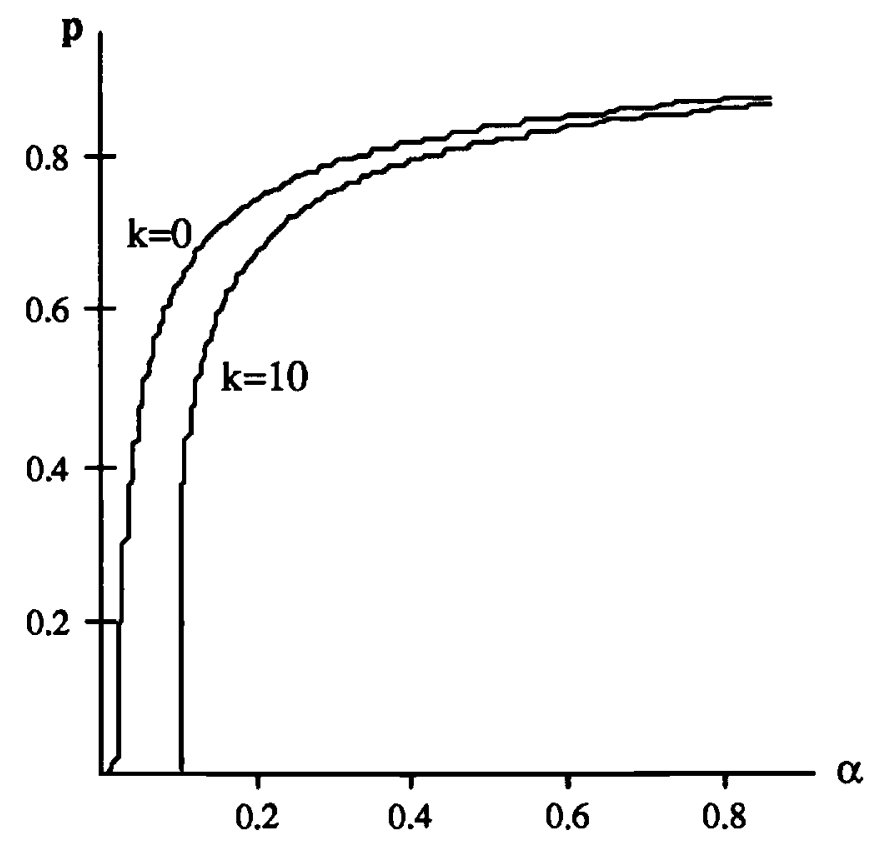

Figure 3

Budget revision probability (p) and the state verification costs (k)

Drawn for $g=100, \lambda=0.3, v=1$.

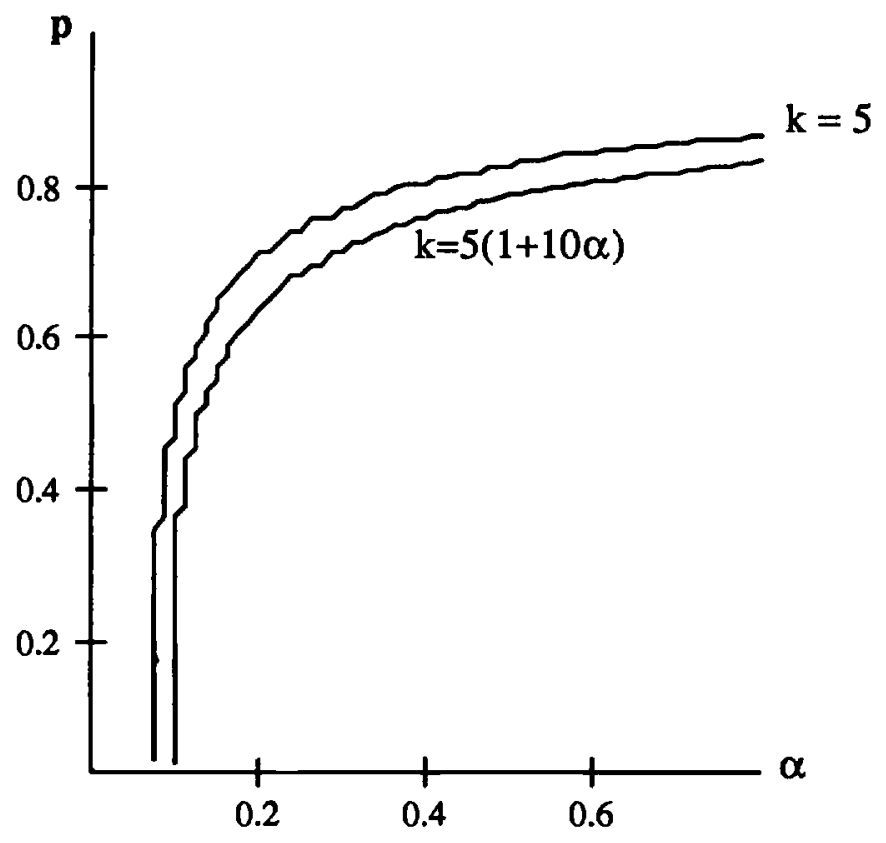

Figure 4

Budget revision probability (p) and volatility dependent state verification costs $[k=k(\alpha)]$ Drawn for $g=100, \lambda=0.3, v=1$. 